\title{
Cost-effectiveness of epidermal growth factor receptor-targeting tyrosine kinase inhibitors
}

Hong Kong Med J 2014;20:465

DOI: 10.12809/hkmj144336

To the Editor-I read with great interest, in the recent issue of the Hong Kong Medical Journal, the article "Effectiveness and cost-effectiveness of erlotinib versus gefitinib in first-line treatment of epidermal growth factor receptor-activating mutation-positive non-small-cell lung cancer patients in Hong Kong" by Lee et al. ${ }^{1}$ The authors, by indirect treatment comparison, demonstrated the cost-effectiveness of erlotinib over gefitinib. However, I find it difficult to understand the rationale behind the basis of this comparison. The approach compares trial [A vs C] with trial [B vs $\mathrm{C}$ ], using $\mathrm{C}$ as the bridge comparator. By substitution, the authors cited IPASS ${ }^{2}$ with gefitinib-treated patients (A) versus carboplatinpaclitaxel-treated patients $(C)$ for comparison with OPTIMAL ${ }^{3}$ with erlotinib-treated patients $(B)$ versus carboplatin-gemcitabine-treated patients (C). Obviously the C's in the two trials are not identical unless it can be proven that carboplatin-paclitaxel and carboplatin-gemcitabine have exactly the same efficacy. Furthermore the patient characteristics in the two trials are also not identical. In IPASS only some patients were shown to have epidermal growth factor receptor (EGFR) mutations, while in OPTIMAL all patients had EGFR-activating mutations in exons 19 and 21. Since such mutations determine the response to treatment targeting tyrosine kinase inhibitors, patients receiving erlotinib (in OPTIMAL) had a clear advantage.

As Lam and Mok $^{4}$ pointed out in their editorial commentary, head-to-head comparison is the preferred method of assessment and such studies have been done in Korea, Taiwan and China, showing no significant difference in efficacy between gefitinib and erlotinib except a better toxicity profile for the former. I fully agree with the editors that we should move on beyond these two drugs.

As to cost-effectiveness, it might be worthwhile to take note of a third EGFR inhibitor, icotinib. In a head-to-head comparison trial, ${ }^{5}$ it has been shown to be non-inferior to gefitinib but with an even better toxicity profile. Developed in China, it is said to cost considerably less than either erlotinib or gefitinib. Hope it becomes available in Hong Kong soon.

John SM Leung *, FCSHK, FHKAM (Surgery)

St Paul's Hospital, Hong Kong

* Corresponding author: leungsiumanjohn@yahoo.com.hk

\section{Declaration}

No conflicts of interests were declared by author.

\section{References}

1. Lee VW, Schwander B, Lee VH. Effectiveness and costeffectiveness of erlotinib versus gefitinib in first-line treatment of epidermal growth factor receptor-activating mutation-positive non-small-cell lung cancer patients in Hong Kong. Hong Kong Med J 2014;20:178-86.

2. Fukuoka M, Wu YL, Thongprasert S, et al. Biomarker analyses and final overall survival results from a phase III randomized, open-label, first-line study of gefitinib versus carboplatin/paclitaxel in clinically selected patients with advanced non-small-cell lung cancer in Asia (IPASS). J Clin Oncol 2011;29:2866-74.

3. Zhou C, Wu YL, Liu X, et al. Overall survival (OS) results from OPTIMAL (CTONG0802), a phase III trial of erlotinib (E) versus carboplatin plus gemcitabine (GC) as first-line treatment for Chinese patients with EGFR mutationpositive advanced non-small cell lung cancer (NSCLC) [abstract]. J Clin Oncol 2012;30(Suppl);abstract 7520.

4. Lam KC, Mok TS. Comparison is beyond IPASS and OPTIMAL. Hong Kong Med J 2014;20:176-7.

5. Shi Y, Zhang L, Liu X, et al. Icotinib versus gefitinib in previously treated advanced non-small-cell lung cancer (ICOGEN): a randomised, double-blind phase 3 noninferiority trial. Lancet Oncol 2013;14:953-61. 